\title{
Oxidative methyl esterification of aldehydes promoted by molecular and hypervalent (III) iodine
}

\author{
N.N. Karade*, V.H. Budhewar, A.N. Katkar, and G.B. Tiwari \\ School of Chemical Sciences,Swami Ramanand Teerth Marathwada University, \\ Nanded - 431606 (Maharashtra, India) \\ E-mail: nnkarade@rediffmail.com
}

\begin{abstract}
A simple and mild new procedure for the facile direct oxidative methyl esterification of aldehydes using molecular iodine in combination with (diacetoxyiodo)benzene in methanol is described. Oxidative esterification is induced by iodonium ion generated in situ by the chemical oxidation of molecular iodine with (diacetoxyiodo)benzene.
\end{abstract}

Keywords: Molecular iodine, (diacetoxyiodo)benzene, oxidation, ester, acetylhypoiodite

\section{Introduction}

The direct oxidative transformation of aldehydes to esters in an extremely useful and selective functional group interconversion in organic synthesis. ${ }^{1} \mathrm{~A}$ two-step reaction sequence involving the oxidation of hemiacetal, ${ }^{2}$ acetal $^{3}$ or cyanohydrin ${ }^{4}$ can bring about this conversion. Several one-pot conversions using different transition metal oxidants such as pyridinium dichromate, ${ }^{5}$ $\mathrm{MnO}_{2},{ }^{6}$ methyltrioxorhenium, ${ }^{7}$ rhodium ${ }^{8}$ or expensive silver ${ }^{9}$ have been reported. The efficiency of this strategy has been improved by including hydrogen peroxide ${ }^{10}$ as the principal oxidant coupled with a catalytic quantity of $\mathrm{V}_{2} \mathrm{O}_{5}{ }^{11}$ and titanosilicate. ${ }^{12}$ The other oxidative esterification protocol uses halogen derived oxidants such as $N$-halosuccinimide, ${ }^{13}$ hypochlorites, ${ }^{14}$ pyridiniumhydrobromide perbromide ${ }^{15}$ and molecular bromine. ${ }^{16}$ Despite these intensive efforts for oxidative esterification of aldehydes, the development of a more effective and mild method still remains interesting since many of the known methods require toxic heavy metal oxidants, dry reaction conditions, longer reaction time and poor yields of the products.

In the past decade, there has been increasing interest by organic chemists in the oxidizing properties of hypervalent iodine compounds. ${ }^{17}$ (Diacetoxyiodo)benzene (DIB), is the most extensively utilised hypervalent iodine (III) reagent, which is easy to handle, non-toxic, commercially available and is similar in reactivity to heavy metal oxidants. ${ }^{18}$ The oxidizing capacity of this versatile class of hypervalent iodine reagents is extensively investigated for the 
oxidation of alcohols but there is hardly any report on the direct oxidative esterfication of aldehydes. Recently, we have revealed that DIB combined with a catalytic quantity of molecular iodine can oxidize alcohols to ketones, acids and esters under mild reaction conditions. ${ }^{19}$ In continuation of this work, we wish to report herein the use of DIB combined with molecular iodine in the facile and direct oxidative methyl esterification of aldehydes (Scheme 1).

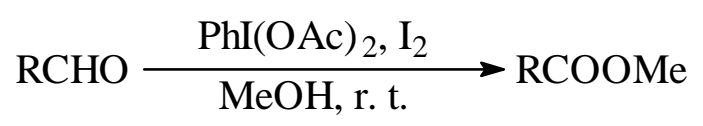

\section{Scheme 1}

\section{Results and Discussion}

To study this process, we have examined the model reaction of benzaldehyde (1 mmol) with molecular iodine $(0.5 \mathrm{mmol})$ in methanol $(10 \mathrm{ml})$. When DIB (1.1 mmol) was added to the above stirred reaction mixture at room temperature, the red brown colour of iodine almost disappeared initially and again reappeared as the reaction progressed towards completion. After stirring above reaction mixture for 13 hours at room temperature, the corresponding methyl benzoate was obtained in $71 \%$ yield. However, the enhancement in the yield (83\%) of methyl benzoate can remarkably be achieved by adding 1.7 equivalents of DIB with respect to the substrate aldehydes. In the above reaction, DIB does not bring about esterification without the molecular iodine and the molecular iodine alone fails to bring about esterification. The optimum yield of the product is obtained when a molar ratio of DIB to molecular iodine of $1.7: 0.5$ is used. Having succeeded with methylbenzoate formation, attempts were made at forming the ethyl or isopropyl esters of benzaldehyde by using ethanol or isopropanol as solvents. In this case, ethyl benzoate and isopropylbenzoate were formed in poor yields of $48 \%$ and $32 \%$ yields respectively. However, the formation of t-butyl ester of benzaldehyde was not observed under similar experimental conditions using t-BuOH as reaction solvent.

It is important to note that iodination product of any aromatic aldehydes was not observed under the above reaction conditions as well as in acetonitrile as reaction solvent. When aromatic aldehydes were treated with $\mathrm{DIB} / \mathrm{I}_{2}$ in acetonitrile medium at room temperature stirring for 24 hours, the starting aldehydes were found to be recovered in quantitative amount.

The potential scope of this oxidative esterification was then extended to a range of various aromatic and aliphatic aldehydes (Table 1). Thus the methoxy substituted aromatic aldehydes (entries b-d) underwent a clean oxidative esterification to form corresponding methyl esters. This is in contrast to the formation of Dakin reaction product using the oxone ${ }^{20}$ or titanosilicates / $\mathrm{H}_{2} \mathrm{O}_{2}{ }^{12}$ combination. 
Table 1. Oxidative methyl esterification of aldehydes using $\mathrm{DIB} / \mathrm{I}_{2}{ }^{\mathrm{a}}$



${ }^{a}$ All the reactions were carried out in methanol at room temperature stirring.

${ }^{\mathrm{b}}$ Isolated yields. 
Similarly, other aromatic aldehydes (entries e-i) with electron releasing and withdrawing substituents underwent oxidative methyl esterification in excellent yields. The reaction of cinnamaldehyde (entry j) with DIB / $\mathrm{I}_{2}$ in methanol produces exclusively methyl cinnamate in 83\% yield, without any observable reaction at the double bond functionality. Finally, the aliphatic aldehydes (entries k-l) also gave the corresponding methyl esters in good yields.

The reasonable mechanism for oxidative methyl esterification of aldehydes using DIB / $\mathrm{I}_{2}$ in methanol is shown in Scheme 2. There is evidence in literature that iodonium ion generated by electrochemical oxidation of iodide anion can induce oxidative esterification of aldehydes. ${ }^{22}$ Recently, it has also been proposed that (diacetoxyiodo)benzene oxidizes molecular iodine to iodonium ion via acetylhypoiodite as putative intermediate, which is subsequently exploited in the iodohydroxylation of olefins ${ }^{23}$ as well as nuclear iodination of electron rich arenes. ${ }^{24}$ As a logical consequence of these two facts, we believe that the oxidative esterification of aldehydes is induced by iodonium ion generated by the chemical oxidation of molecular iodine with (diacetoxyiodo)benzene. Thus, the initially formed methyl hemiacetal $\mathbf{4}$ is oxidized by acetylhypoiodite $\mathbf{2}$ to the corresponding hemiacetal hypoiodite $\mathbf{6}$. Another equivalent of acetyl hypoiodite will promote the concomitant oxidation of hemiacetal hypoiodite to methyl esters 7.
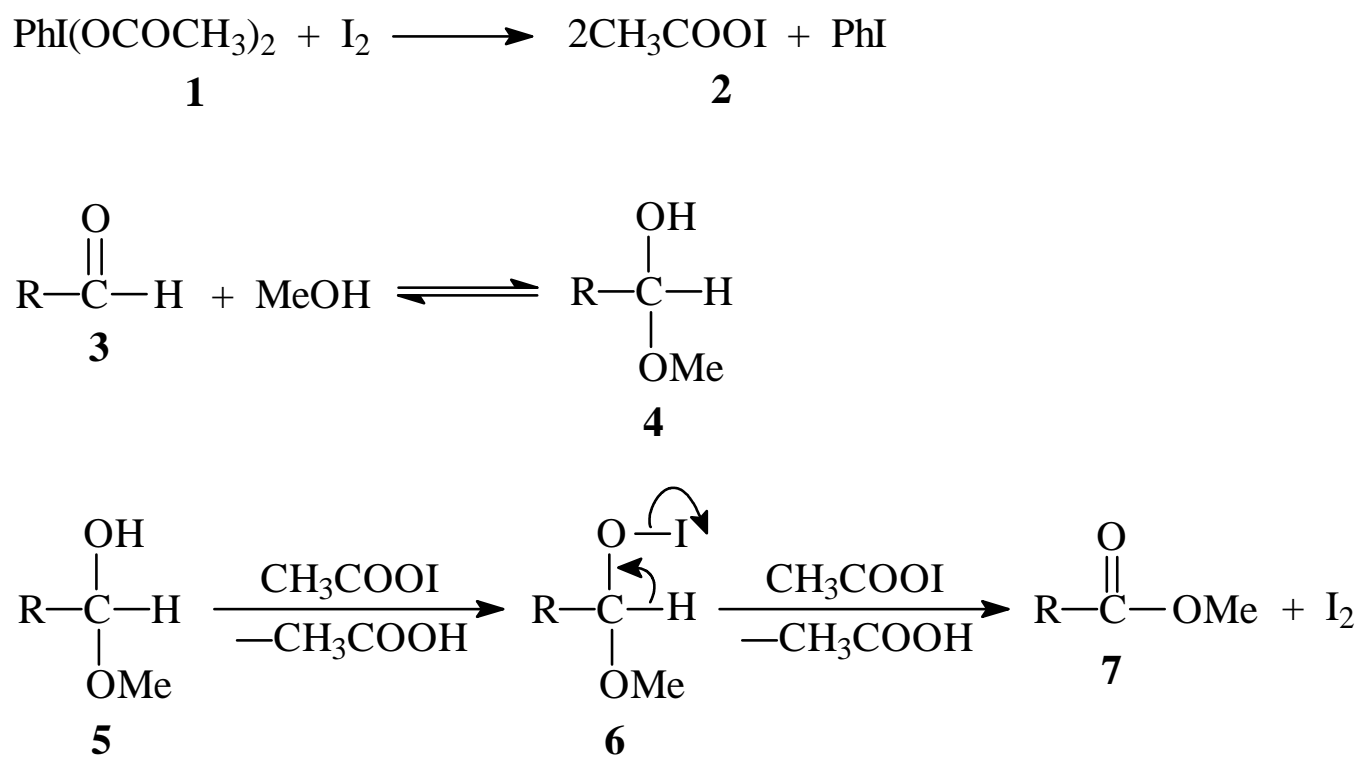

\section{Scheme 2}

In conclusion, a transition metal-free protocol for oxidative esterification of aldehydes has been developed using (diacetoxyiodo)benzene in combination with molecular iodine. Although the literature enumerates a number of procedures for conversion of aldehydes to esters, the environmentally benign nature of DIB and $\mathrm{I}_{2}$, mild reaction conditions, high yields of the products and experimental simplicity makes it a practical alternative. 


\section{Experimental Section}

To a magnetically stirred solution of aldehyde $(1 \mathrm{mmol})$, iodine $(0.5 \mathrm{mmol})$ in $\mathrm{MeOH}(15 \mathrm{ml})$ was added (diacetoxyiodo)benzene $(1.7 \mathrm{mmol})$. The resulting red brown solution was stirred in an open vessel for the time as mentioned in Table 1 . Progress of the reaction was monitored by TLC. The red brown colour of iodine almost disappeared within half an hour and again reappeared as the reaction progressed towards completion. After completion of reaction, the mixture was washed with $\mathrm{Na}_{2} \mathrm{~S}_{2} \mathrm{O}_{3}$ and extracted with $\mathrm{CH}_{2} \mathrm{Cl}_{2}(2 \times 10 \mathrm{ml})$. The organic extract was dried over anhydrous $\mathrm{Na}_{2} \mathrm{SO}_{4}$. Removal of the solvent and subsequent silica gel chromatography (petroleum ether and EtOAc) afforded the corresponding methyl esters in the pure from.

\section{Acknowledgement}

The authors are thankful to Department of Science and Technology, New Delhi for the financial support (No. SR/FTP/CS-77/2005).

\section{References}

1. (a) Larock, R. C. In Comprehensive Organic Transformations; VCH: New York, 1989, pp 840. (b) March, J. Advanced Organic Chemistry, John Wiley and Sons, New York, 1992, pp 1196.

2. Craig, J. C.; Harning, E. C. J. Org. Chem. 1960, 25, 2098.

3. Mavel, E. N.; Jonicich, M. J. J. Am. Chem. Soc. 1951, 73, 973.

4. (a) Adams, A. D.; Schlessinger, R. H.; Tata, J. R.; Venit, J. J. J. Org. Chem. 1986, 51, 3070.

(b) Corey, E. J.; Gilman, M. W.; Granem, B. E. J. Am. Chem. Soc. 1968, 90, 5616.

5. O'Conner, B.; Just, G. Tetrahedron Lett. 1987, 28, 3235.

6. Bal, B. S.; Childers, Y. W.; Pinnick, H. W. Tetrahedron 1981, 37, 2091.

7. Espenson, J. H.; Zhu, Z.; Zauche, T. H. J. Org. Chem. 1999, 64, 1191.

8. Grigg, R.; Mitchell, T. R. B.: Sutthivaiyakit, S. Tetrahedron 1981, 37, 4313.

9. Thomason, S. C.; Kubler, D. G. J. Chem. Educ. 1968, 45, 546.

10. Sato, K.; Hyodo, M.; Takagi, J.; Aok, M.; Noyori, R. Tetrahedron Lett. 2000, 41, 1439.

11. Gopinath, R.; Patel, B. K. Org. Lett. 2000, 5, 577.

12. Chavan, S. P.; Danatle, S. W.; Gavande, C. A.; Venkataraman, M. S.; Praveen, C. Synlett 2002, 2, 267.

13. (a) Ogawa, T.; Matsui, M. J. Am. Chem. Soc. 1976, 98, 1629. (b) McDonald, C.; Holcomb, H.; Kennedy, K; Kirkpatrick, E.; Leathers, T.; Veneman, P. J. Org. Chem. 1989, 54, 1213. 
14. Stevens, R. V.; Champman, K. T.; Stubbs, C. A.; Tam, W. W.; Albizati, K. F. Tetrahedron Lett. 1982, 23, 4647.

15. Sayama, S.; Onami, T. Synlett 2004, 2739.

16. Venkataramy, S. D.; Cleveland, J. H.; Pearson, D. E. J. Org. Chem. 1979, 44, 3082.

17. (a) Moriatry, R. M. J. Org. Chem. 2005, 70, 2893. (b) Stang, P. J. J. Org. Chem. 2003, 68, 2997. (c) Zhdankin, V. V.; Stang, P. J. Chem. Rev. 2002, 102, 2523. (d) Moriatry, R. M.; Prakash, O. Org. React. 2002, 57, 327.

18. Varvoglis, A. Hypervalent Iodine in Organic Synthesis; Academic Press: London, 1997; Chapter 3, p19.

19. Karade, N. N.; Tiwari, G. B.; Huple, D. B. Synlett 2005, 2039.

20. Travis, B. R.; Sivakumar, M.; Hollist, G. O.; Barhan, B. Org. Lett. 2003, 5(7), 1031.

21. Shono, T.; Matsumura, Y.; Hayashi, J.; Inoue, K.; Iwasaki, F.; Itoh, T. J. Org. Chem. 1985, 50, 4967.

22. Corso, A. R. D.; Panunzi, B.; Tingoli, M. Tetrahedron Lett. 2001, 42, 7245.

23. (a) Panunzi, B.; Ritiroti, L.; Tingoli, M. Tetrahedron Lett. 2003, 44, 8753. (b) D'Auria, M.; Mauriello, G. Tetrahedron Lett. 1995, 36, 4883. (c) Merkushev, E. B.; Simakhina, N. D.; Koveshnikova, G. M. Synthesis 1980, 486.

24. (a) Dictionary of Organic Compounds, Chapman and Hall: London, 6th Edn., 1996. (b) Aldrich Catalogue of Chemicals, 2003. 